\title{
The Role of Important Non-Parental Adults (VIPs) in the Lives of Older Adolescents: A Comparison of Three Ethnic Groups
}

\author{
Eileen Haddad · Chuansheng Chen • \\ Ellen Greenberger
}

Received: 17 December 2009/Accepted: 21 April 2010/Published online: 6 May 2010

(C) The Author(s) 2010. This article is published with open access at Springerlink.com

\begin{abstract}
Previous research has consistently documented the importance of VIPs (mentors or important non-parental adults) in the lives of adolescents. Little is known, however, about whether VIPs play the same important roles across ethnic groups and whether VIPs remain influential when adolescents are older and involved in romantic relationships. The present study compared VIPs of 355 Hispanic, Asian, and European American older adolescents (age range $=17-19$ years; $M=18.7$ years; $62 \%$ female). Results indicated that, despite ethnic differences in their social capital, VIPs' psychological characteristics (e.g., warmth and acceptance, depressive symptoms, and problem behavior) were similar. VIPs were perceived to have more positive psychological profiles than parents and peers, and in some cases, romantic partners. Moreover, with a few exceptions, the associations between VIP characteristics and adolescent adjustment (e.g., self-esteem, depressive symptoms, and problem behavior) were largely similar across ethnic groups. Finally, VIPs made unique contributions to adolescents' self-esteem and problem behaviors even after the effects of romantic partners were considered. Implications of the findings are discussed.
\end{abstract}

\footnotetext{
E. Haddad $(\square) \cdot$ E. Greenberger

Department of Psychology and Social Behavior, University of California-Irvine, 4201 Social and Behavioral Sciences Gateway, Irvine, CA 92697, USA

e-mail: ehaddad@uci.edu

E. Greenberger

e-mail: egreenbe@uci.edu

\section{Chen}

Department of Psychology and Social Behavior and Education, University of California-Irvine, 4201 Social and Behavioral Sciences Gateway, Irvine, CA 92697, USA

e-mail: cschen@uci.edu
}

Keywords Adolescent adjustment · Mentors · Ethnic differences - Social relationships . Romantic relationships

Although parents and peers are arguably the most important influences on adolescents, previous research has consistently documented the valuable role of non-parental adults such as natural mentors and VIPs (non-parental adults whom youth identify as important figures in their lives) in adolescent development (e.g., DuBois and Karcher 2005; Greenberger et al. 1998). The influence of natural mentors and VIPs in adolescents' lives is widespread, with research indicating that characteristics of VIPs are associated with adolescents' academic (e.g., educational expectations), social (e.g., problem behaviors), and emotional well-being (e.g., depression) (Chang et al. in press; DuBois and Silverthorn 2005; Greenberger et al. 1998; Zimmerman et al. 2002), and do so in different cultures (Chen et al. 2003; Darling et al. 2002). Furthermore, VIPs have been found to make unique and independent contributions to adolescent adjustment after both parental and peer effects are considered (Beam et al. 2002; Greenberger et al. 1998). However, this literature has not directly compared VIPs across ethnic groups and has not examined whether VIPs continue to play an important role among older adolescents who are involved in romantic relationships. The present study addresses these two limitations.

Previous research has indicated that the characteristics of VIPs (mentors or other important non-parental adults) are closely related to adolescent psychosocial adjustment. For example, high perceived warmth and acceptance from VIPs has been found to be associated with higher selfesteem and fewer depressive symptoms among adolescents (DuBois and Silverthorn 2005; Greenberger et al. 1998; 
Rhodes et al. 1992). Additionally, adolescents with VIPs who engaged in good "role-model" behavior and showed disapproval of the adolescents' involvement in misconduct, were less likely to exhibit problem behaviors, regardless of the behavior of their peers and parents (Greenberger et al. 1998). Non-parental adults have been shown to be particularly influential in the lives of at-risk adolescents. For example, at-risk adolescents with natural mentors are more likely to pursue higher education and are less likely to engage in risky behaviors than those without a natural mentor (DuBois and Silverthorn 2005; Zimmerman et al. 2002). Additionally, in studies of pregnant and parenting African American teens, Rhodes et al. (1992) found that teenage mothers who had a person they considered a mentor experienced lower levels of depressive symptomatology, more positive attitudes toward career attainment, and greater optimism about life. Thus, among adolescents, including those who are at-risk, the characteristics of VIPs are associated with a range of psychological, emotional, and behavioral outcomes.

Previous research has also demonstrated that VIPs are an important aspect of adolescents' lives in various ethnic groups and for youths in different countries. For example, among African-Americans, perceived support from adolescent girls' mothers declined over time, but perceived support from their natural mentors did not decrease (Klaw et al. 2003; Zimmerman et al. 2002). Likewise, Latina adolescents with natural mentors experienced less distress and better coping skills compared to Latinas without a natural mentor (Rhodes et al. 1994). A study by Sanchez et al. (2008) also found natural mentoring relationships to be beneficial to adolescent Latinos/as with respect to their academic performance. Specifically, among Latino/a adolescents, the presence of a mentor was associated with fewer school absences and higher educational expectations (Sanchez et al. 2008). VIPs also have been shown to be an important part of the social context for adolescent development in different cultural groups such as Chinese and Japanese (Chen et al. 2003; Darling et al. 2002). Clearly, VIPs play important roles in the lives of adolescents from diverse ethnic and cultural backgrounds.

Although the importance of VIPs among adolescents is clear, the lack of direct comparisons across ethnic groups leaves open the question of whether the role of VIPs varies by adolescents' ethnicity. Previous research has shown that a great majority of VIPs are of the same ethnicity as the adolescents (DuBois et al. 2002; Rhodes et al. 2002). Given the ethnic inequalities in social capital and other resources, VIPs from different ethnic groups may have different socio-economic profiles. Nonetheless, several studies suggest that the role VIPs play in adolescents' lives may be mostly similar across ethnic groups. For example, in a study of adolescents in China and the U.S., Chen et al.
(2003) found very few significant differences (2 out of 16 pairs of correlations) in the associations between VIP characteristics and measures of adolescent adjustment. Additionally, much work suggests similarities in general developmental processes across ethnic groups (e.g., Rowe et al. 1994; Wissink et al. 2009). For example, Rowe et al. (1994) compared the covariance matrices of U.S. Black, Hispanic, White, and Asian adolescents across a wide range of variables (e.g., academic achievement, problem behaviors, parental involvement, self-esteem) and found them to be nearly identical, no more different than random halves within a single ethnic group. These types of findings suggest that similarities in developmental processes may exist despite often-present ethnic differences in mean levels of the variables examined.

Importantly, VIPs have been demonstrated to make independent contributions to adolescent development even after the contributions of other individuals in adolescents' lives have been taken into account. Most of this work has been based on comparisons with parents and peers (Chang et al. in press; Greenberger et al. 1998). For example, studies have found that VIPs have both parent- and peerlike qualities, and may serve as better role models (e.g., lower levels of psychological and behavioral problems) for adolescents than do parents and peers (Beam et al. 2002). Additionally, VIPs often provide more social support (e.g., higher levels of warmth and acceptance) than parents and peers (Chen et al. 2003). Studies have also found that the characteristics of VIPs (e.g., warmth and acceptance, problem behavior) accounted for unique variance in adolescent outcomes such as misconduct and depressive symptoms after analogous measures of parents and peers were considered (Chang et al. in press; Greenberger et al. 1998). Together, these studies point to the distinct and often positive role VIPs can play in adolescents' lives.

The influence of VIPs, however, has not been considered in the context of romantic partners, despite the fact that romantic relationships are an important part of many late adolescents' lives. Research that addresses the influence of romantic relationships on adolescent development is limited and inconclusive. For example, some studies have found that romantic involvement in adolescence is associated with increased social competence and selfesteem, and that romantic partners are an important source of social support for adolescents (Connolly et al. 1999). However, other studies report that romantic relationships during adolescence are related to negative outcomes such as depressive symptoms (Davilla et al. 2004) and problem behaviors (Neeman et al. 1995; Rhule-Louie and McMahon 2007; Zimmer-Gembeck et al. 2001). Furthermore, the influence of adolescent romantic relationships in the context of other existing relationships (e.g., with parents, peers, and VIPs) remains largely unexplored, with a few 
exceptions. A study by Overbeek et al. (2003) found that the associations between parental attachment and emotional disturbance were weaker for adolescents in romantic relationships than adolescents not in romantic relationships (Overbeek et al. 2003). The authors concluded that the influence of parental relationships diminishes during late adolescence due to the increased intimacy of romantic relationships. However, other studies suggest that romantic relationships complement rather than interrupt other close relationships (Collins and Laursen 2004; Furman et al. 2002; McMahon and Wilkinson 2005). For example, a study by McMahon and Wilkinson (2005) examined whether romantic relationships replace the influence of parent and peer relationships on adolescent psychological health and concluded that romantic relationships during adolescence have only minor influences on other existing relationships. Little is known, however, about the influence of VIPs when adolescents are involved in romantic relationships.

\section{The Current Study}

The current study compared the characteristics and roles of VIPs across three ethnic groups (Hispanic, Asian, and European Americans) and examined whether VIPs made unique contributions even when older adolescents had romantic partners. Our first research objective was to ascertain whether the characteristics of VIPs vary by adolescents' ethnicity. Given that most VIPs are from adolescents' own ethnic group, our first hypothesis was that VIPs' demographic characteristics and social capital (e.g., educational attainment, employment status, and occupational prestige) would reflect broader differences in the population. More specifically, the VIPs of Hispanic Americans were expected to have lower levels of educational attainment, less likelihood of employment, and lower levels of occupational prestige than the VIPs of Asian Americans and European Americans. Second, we hypothesized that VIPs' psychological characteristics (e.g., depressive symptoms, problem behaviors, and warmth and acceptance) would be similar across all three ethnic groups. This hypothesis was based on evidence suggesting that VIPs are selected by adolescents for qualities that are selfaffirming or supportive (Greenberger et al. 1998). Given that adolescents perceive VIPs as having more positive characteristics than their parents and friends (Chen et al. 2003), we expected the positive perception of VIPs to replicate across all three ethnic groups and extend to romantic partners.

An additional research aim was to determine whether the associations between VIP characteristics and adolescent outcomes vary by adolescents' ethnicity. In general, we expected few ethnic differences in such associations (our third hypothesis). This hypothesis was based on two types of evidence. First, there is much evidence for similarities in general developmental processes across ethnic groups (e.g., Rowe et al. 1994). Second and more relevant, in a study comparing Chinese and U.S. adolescents, there were very few differences in the associations between VIP characteristics and adolescent adjustment (Chen et al. 2003).

Our final research objective was to determine whether VIP characteristics make unique contributions to adolescents' adjustment after analogous characteristics of the adolescents' romantic partner and peers are taken into account. Our fourth hypothesis was that VIPs would continue to play a unique and significant role even when adolescents were involved in romantic relationships. This hypothesis was based on evidence pointing to the uniqueness of the role of VIPs and on the typical similarities between romantic partners and peers (e.g., age, interests, activities) (Greenberger et al. 1998).

\section{Methods}

\section{Data and Participants}

As part of a larger project, data were collected from students at four different high schools in the Los Angeles Unified School District. The participants were initially recruited during their senior year of high school, but information on romantic partners was not collected at that time. Data for the present study are from Wave 2 (1 year post-high school), when information about romantic partners, VIPs, parents and peers is available. The sample for this study was restricted to a subgroup of adolescents in Wave 2 that indicated they had a VIP (66\%). Three ethnic groups with adequate sample size were the focus of our analysis: Asians $(N=96)$, Hispanics $(N=144)$, and European Americans $(N=115)$. Females made up $62.3 \%$ of the sample, and the average age was 18.7 years $(\mathrm{SD}=.56)$. Most participants were in their first year of college and were from working- and middle- class backgrounds. Adolescents most frequently identified siblings $(22.5 \%)$, older friends $(18.6 \%)$, or aunts/uncles $(15.8 \%)$ as their VIPs, however other common groups included grandparents $(8.9 \%)$, cousins $(6.7 \%)$ and teachers $(5.0 \%)$. There were no ethnic differences in whether VIPs were kin or non-kin, with about half of each ethnic group indicating their VIP is kin (Asians $=53.7 \%$, Hispanics $=51.4 \%$, and European Americans $=50.0 \%$, respectively). Analyses involving romantic partners were conducted on the subgroup of adolescents who were involved in romantic relationships: Asians $(N=49)$, Hispanics $(N=80)$, and European Americans $(N=66)$. The 
$5.3 \%(N=17)$ of adolescents who identified their romantic partner as their VIP were excluded from analysis sample to avoid confounding the analyses.

\section{Measures}

Measures in this study included VIPs' background characteristics, adolescents' self-esteem, depressive symptoms, and problem behaviors, perceived parental warmth and acceptance, and the perceived warmth and acceptance, depressive symptoms, and problem behaviors of their peers, VIPs, and romantic partners. To satisfy the request of several school principals, participants were not asked to report on their parents' depressive symptoms and problem behaviors.

\section{Background Characteristics}

Background characteristics of VIPs included educational attainment, employment status (employed/not employed), and occupational prestige. In assessing VIPs' educational attainment, adolescents were asked, "How far did this person get in school?" and answered on a scale ranging from $1=$ "did not graduate from high school" to $4=$ "graduated from a 4-year college or higher". With respect to employment status and occupational prestige, adolescents who indicated that their VIP was employed were asked, "What is the title of his or her job?" These responses were coded for occupational prestige based on Nakao and Treas (1994) prestige scores, with scores in this sample ranging from 21 (working with animals in entertainment industry) to 86 (physician). A 10-point difference is the equivalent difference between a journalist (60) and an engineer (70). The coding of occupational prestige was done by two advanced graduate students with knowledge about adult work and occupations; inter-rater agreement was $88 \%$.

\section{Self-Esteem}

Adolescent self-esteem was assessed using the Rosenberg Self-Esteem Scale (Rosenberg 1965). The 10-item scale asked students to rate items like, "On the whole, I am satisfied with myself", and "I take a positive attitude toward myself", on a scale ranging from $1=$ "strongly disagree" to $4=$ "strongly agree". The internal reliability (Cronbach $\alpha$ ) of the scale was acceptable for each ethnic group $(\alpha=.84$ for Hispanics; $\alpha=.85$ for Asians; $\alpha=.88$ for European Americans).

\section{Warmth and Acceptance}

Warmth and acceptance was assessed using the Parental Warmth and Acceptance Scale (Greenberger et al. 1998), and its analogous versions for peers, VIPs, and romantic partners. The 8-item scales included items like, "He/she really understands me", and "I know that he/she will be there for me if I need him/her" and were scored on a scale ranging from $1=$ "strongly disagree" to $6=$ "strongly agree". The reliability (Cronbach $\alpha$ ) for the scale was acceptable across all ethnic groups, ranging from .77 to .86 for the parent scale, from .70 to .74 for the peer scale, from .69 to .74 for the VIP scale, and from .77 to .82 for the romantic partner scale.

\section{Depressive Symptoms}

Depressive symptoms of adolescents were assessed using the 20-item Center for Epidemiologic Studies Depression Scale (CES-D) (Radloff 1977). Items on this scale included, "I felt depressed", and "I could not get going", and were coded on a scale ranging from $1=$ "rarely or none of the time" to $4=$ "most or all of the time". The time frame of the scale was over the last month. Using a 3-item version of the scale with minor modifications (e.g., "I" becomes "he/she"), adolescents also reported on the depressive symptoms of their peers, VIP, and romantic partner (Beam et al. 2002; Farruggia et al. 2006). The reliability (Cronbach $\alpha$ ) of the adolescent scale ranged from .86 to .89 across the three ethnic groups, whereas Cronbach $\alpha$ ranged from .70 to .72 for the peer scale, from .69 to .72 for the VIP scale, and from .71 to .74 for the romantic partner scale.

\section{Problem Behaviors}

Problem behaviors were assessed using a 16-item scale (adapted from Chen et al. 1998) that asked students to indicate how frequently they engaged in various problem behaviors (e.g., smoked cigarettes, threatened to hurt someone, cheated on an exam). The scale ranged from $1=$ "never" to $4=$ "more than 4 times". Adolescents also reported on the problem behaviors of their peers, VIPs and romantic partners on a shorter 10-item scale (Beam et al. 2002; Farruggia et al. 2006). The internal reliability (Cronbach $\alpha$ ) for the adolescent scale ranged from .83 to .86 across ethnic groups, whereas Cronbach $\alpha$ ranged from .78 to .85 for the peer scale, from .71 to .77 for the VIP scale, from .70 to .73 for the romantic partner scale.

\section{Results}

Consistent with our first hypothesis, we found that VIPs varied across ethnic groups in terms of their educational background $\left(\chi^{2}(6)=27.48, p<.001\right)$. The main difference was that the VIPs of Hispanic adolescents had lower 
educational attainment than the VIPs of Asian or European Americans: e.g., $17.1 \%$ of Hispanic youths' VIPs did not graduate from high school, compared to $6.7 \%$ and $5.7 \%$ of VIPs of Asian and European Americans, respectively; and only about one-third graduated from college, compared to well over one-half of Asian Americans' VIPs and twothirds of European Americans' VIPs. We found no ethnic differences in whether VIPs were employed or not (Asians: 81\% employed; European Americans: $80 \%$ employed; Hispanics: $85 \%$ employed). However, ethnic differences were present when considering VIPs' occupational prestige. Specifically, we found that VIPs of Asian adolescents had higher levels of occupational prestige than VIPs of Hispanic and European Americans (Asians: $M=53.10$; Hispanics: $M=47.35$, European Americans: $M=47.54$; $F(2,282)=3.95, p<.05)$. Consistent with our second hypothesis, we found the psychological characteristics (e.g., levels of warmth and acceptance, depressive symptoms, and problem behavior) of VIPs to be similar across ethnic groups (see Table 1 and associated Note 2). Also consistent with this hypothesis, we found that VIPs had more positive psychological profiles than parents and peers, and in some cases, romantic partners: i.e., VIPs were reported to have higher levels of warmth and acceptance than parents and peers, and lower levels of depressive symptoms and problem behaviors than peers, among Asian, Hispanic, and European American adolescents. Additionally, when compared to romantic partners, VIPs were reported to have lower levels of depressive symptoms across ethnic groups, and lower levels of problem behaviors among Hispanics (see Table 1).

In relation to our third hypothesis, as expected, the associations between VIPs' characteristics (e.g., warmth and acceptance, depressive symptoms, and problem behavior) and adolescent adjustment (e.g., self-esteem, depressive symptoms, and problem behavior) were mostly similar across ethnic groups (see Table 2). All significant correlations were in the same direction for the three groups. For example, bivariate correlations indicated that VIP warmth and acceptance was negatively associated with adolescents' depressive symptoms (Asian Americans: $r=-.45, p<$ .001 ; Hispanic Americans: $r=-.33, p<.001$; European Americans: $r=-.23, p<.01$ ), and positively associated with adolescents' self-esteem across ethnic groups (Asian Americans: $r=.53, p<.001$; Hispanic Americans: $r=$ $.36, p<.001$; European Americans: $r=.34, p<.001)$. Likewise, VIPs' problem behaviors had a consistently positive association with adolescents' own problem behaviors (Asian Americans: $r=.27, p<.01$; Hispanic Americans: $r=.33, p<.01$; European Americans: $r=.55$, $p<.001)$. Fisher $\mathrm{r}-\mathrm{to}-\mathrm{z}$ transformations revealed five significant differences between correlations (out of the 27 pairs of correlations that were compared). VIP warmth and acceptance was more strongly associated with self-esteem among Asian adolescents than European American adolescents $(z=2.02, p<.05)$, and VIP problem behaviors were more strongly related to the problem behaviors of European American adolescents than Asians and Hispanics $(z=2.46$,

Table 1 Means of warmth and acceptance, depressive symptoms, and problem behavior and associated $t$-tests

\begin{tabular}{|c|c|c|c|c|c|c|c|}
\hline & \multirow[t]{2}{*}{ Parents } & \multirow[t]{2}{*}{ Peers } & \multirow{2}{*}{$\begin{array}{l}\text { Romantic } \\
\text { partners }\end{array}$} & \multirow[t]{2}{*}{ VIPs } & \multicolumn{3}{|l|}{$t$-tests } \\
\hline & & & & & $\begin{array}{l}\text { VIPs vs. } \\
\text { parents }\end{array}$ & $\begin{array}{l}\text { VIPs vs. } \\
\text { peers }\end{array}$ & $\begin{array}{l}\text { VIPs vs. } \\
\text { romantic } \\
\text { partners }\end{array}$ \\
\hline \multicolumn{8}{|l|}{ Asian Americans } \\
\hline Warmth and acceptance & $4.59(.98)$ & $5.00(.69)$ & $5.36(.73)$ & $5.28(.66)$ & $6.74 * * *$ & $3.08 * *$ & -0.43 \\
\hline Depressive symptoms & & $.40(.34)$ & $.36(.35)$ & $.19(.27)$ & & $-5.38 * * *$ & $-2.40^{*}$ \\
\hline Problem behavior & & $.16(.21)$ & $.09(.16)$ & $.05(.13)$ & & $-4.71 * * *$ & -1.81 \\
\hline \multicolumn{8}{|l|}{ Hispanic Americans } \\
\hline Warmth and acceptance & $4.65(.86)$ & $4.93(.74)$ & $5.15(.79)$ & $5.24(.61)$ & $6.68 * * *$ & $5.37 * * *$ & 0.74 \\
\hline Depressive symptoms & & $.31(.34)$ & $.33(.35)$ & $.15(.26)$ & & $-4.24 * * *$ & $-3.34 * * *$ \\
\hline Problem behavior & & $.16(.21)$ & $.11(.18)$ & $.06(.13)$ & & $-4.39 * * *$ & $-3.37 * *$ \\
\hline \multicolumn{8}{|l|}{ European Americans } \\
\hline Warmth and acceptance & $4.91(.87)$ & $5.11(.72)$ & $5.24(.72)$ & $5.39(.63)$ & $4.85 * * *$ & $3.08 * *$ & 1.38 \\
\hline Depressive symptoms & & $.36(.36)$ & $.32(.36)$ & $.17(.26)$ & & $-4.89 * * *$ & $-2.93 * *$ \\
\hline Problem behavior & & $.29(.27)$ & $.12(.16)$ & $.09(.14)$ & & $-8.44 * * *$ & -1.95 \\
\hline
\end{tabular}

Standard deviations of the means are in the parentheses

VIPs' mean warmth and acceptance, depressive symptoms, and problem behaviors did not differ across ethnic groups

$* p<.05 ; * * p<.01 ; * * * p<.001$ 
Table 2 Bivariate correlations between social context and adolescent adjustment

\begin{tabular}{|c|c|c|c|c|c|c|c|c|c|}
\hline & \multicolumn{3}{|c|}{ Asian Americans } & \multicolumn{3}{|c|}{ Hispanic Americans } & \multicolumn{3}{|c|}{ European Americans } \\
\hline & $\begin{array}{l}\text { Depressive } \\
\text { symptoms }\end{array}$ & $\begin{array}{l}\text { Self- } \\
\text { esteem }\end{array}$ & $\begin{array}{l}\text { Problem } \\
\text { behavior }\end{array}$ & $\begin{array}{l}\text { Depressive } \\
\text { symptoms }\end{array}$ & $\begin{array}{l}\text { Self- } \\
\text { esteem }\end{array}$ & $\begin{array}{l}\text { Problem } \\
\text { behavior }\end{array}$ & $\begin{array}{l}\text { Depressive } \\
\text { symptoms }\end{array}$ & $\begin{array}{l}\text { Self- } \\
\text { esteem }\end{array}$ & $\begin{array}{l}\text { Problem } \\
\text { behavior }\end{array}$ \\
\hline \multicolumn{10}{|l|}{ Parents } \\
\hline Warmth and acceptance & $-.39 * * *$ & $.36 * * *$ & .05 & $-.40 * * *$ & $.44 * * *$ & -.16 & $-.44 * * *$ & $.57 * * *$ & -.18 \\
\hline \multicolumn{10}{|l|}{ Peers } \\
\hline Warmth and acceptance & $-.49 * * *$ & $.53 * * *$ & .07 & $-.35 * * *$ & $.37 * * *$ & -.09 & $-.34 * *$ & $.42 * * *$ & -.10 \\
\hline Depressive symptoms & $.23 *$ & -.00 & -.00 & $.33 * * *$ & $-.21 *$ & -.01 & .13 & -.11 & .09 \\
\hline Problem behaviors & .05 & .04 & $.49 * * *$ & .17 & -.04 & $.36^{* * *}$ & .14 & -.14 & $.62 * * *$ \\
\hline \multicolumn{10}{|l|}{ Romantic partners } \\
\hline Warmth and acceptance & $-.42 * * *$ & $.49 * * *$ & -.02 & $-.23 *$ & $.24 *$ & -.20 & $-.28 *$ & $.25^{*}$ & -.09 \\
\hline Depressive symptoms & .12 & .16 & -.12 & .11 & -.07 & .09 & .06 & -.20 & -.01 \\
\hline Problem behaviors & .28 & -.23 & $.53 * * *$ & $.28 *$ & -.21 & $.49 * * *$ & .08 & -.12 & $.52 * * *$ \\
\hline \multicolumn{10}{|l|}{ VIPs } \\
\hline Warmth and acceptance & $-.45 * * *$ & $.53 * * *$ & .05 & $-.33 * * *$ & $.36 * * *$ & -.07 & $-.23 * *$ & $.34 * *$ & -.18 \\
\hline Depressive symptoms & .20 & -.14 & .19 & $.21^{*}$ & $-.18^{*}$ & .15 & .15 & -.18 & .17 \\
\hline Problem behaviors & .12 & .01 & $.27 * *$ & $.22 * *$ & $-.29 * * *$ & $.33 * *$ & .16 & -.05 & $.55 * * *$ \\
\hline
\end{tabular}

$* p<.05 ; * * p<.01 ; * * * p<.001$

$p<.05$ and $z=2.19, p<.05$, respectively). Last, VIP problem behavior was negatively associated with the selfesteem of Hispanic adolescents, but not significantly associated with the self-esteem of Asian and European American adolescents $(z=2.33, p<.05$ and $z=1.98, p<.05$, respectively). When examining ethnic differences in the associations between other social contexts (i.e., parents, peers, and romantic partners) and adolescent outcomes, Fisher r-to-z transformations revealed only one difference: i.e., peer problem behaviors were more strongly related to problem behaviors among European American than Hispanic adolescents $(z=2.77, p<.01)$.

To test our fourth hypothesis, that VIPs' attributes would make unique contributions to adolescent adjustment (e.g., self-esteem, depressive symptoms, and problem behaviors) even after the characteristics of parents, peers, and romantic partners were considered, we conducted a series of regression analyses. These analyses examined the effects of the psychological features of parents, peers, VIPs and romantic partners on adolescent adjustment. In preliminary regression models (analyses not shown), interaction terms between ethnicity and the psychological features that had shown significant ethnic differences in bivariate correlations were included. With other variables in the regression, the interaction terms were no longer significant. For this reason, and in order to have adequate statistical power (given the smaller sample who had romantic partners), we controlled for, rather than examined, ethnicity in the final analyses. Furthermore, since it is possible for the effects of romantic partners on adjustment to be different for males and females, we also controlled for gender in the regressions.
As seen in Table 3, VIPs' perceived characteristics made unique contributions to adolescents' self-esteem and problem behaviors after the effects of romantic partners were accounted for $(b=.10, p<.05$, and $b=.64$, $p<.05$, respectively). VIPs' characteristics, however, did not make unique contributions to adolescents' depressive symptoms. Additionally, we found that parent and peer warmth and acceptance made unique contributions to adolescent self-esteem $(b=.14, p<.001$ and $b=12$, $p<.01$, respectively) and depression $(b=-.10, p<.01$ and $b=-.14, p<.01$ ), and that peers' depressive symptoms and problem behaviors made unique contributions to adolescents' own depressive symptoms and problem behaviors ( $b=.33, p<.01$ and $b=.52, p<.01$, respectively). Interestingly, when considering the characteristics of romantic partners, only romantic partners' problem behavior made an independent contribution to adolescent adjustment: i.e., to a higher level of adolescents' own problem behavior $(b=.94, p<.001)$.

\section{Discussion}

Previous research has clearly documented the important role of VIPs and natural mentors in adolescent lives. However, previous work has left open the questions of whether the characteristics and influence of VIPs varies by ethnicity, and whether VIPs remain influential when adolescents are involved in romantic relationships. The present study directly compared the VIPs of adolescents across three ethnic groups (Hispanic, Asian, and European 
Table 3 Regression of adolescent adjustment on features of the social context, controlling for gender and ethnicity

\begin{tabular}{|c|c|c|}
\hline & $\mathrm{B}(\mathrm{se})$ & Beta \\
\hline \multicolumn{3}{|c|}{ Adolescent self-esteem and warmth and acceptance in social context } \\
\hline VIP & $.10(.04)^{*}$ & .20 \\
\hline Parent & $.14(.03)^{* * *}$ & .28 \\
\hline Peer & $.12(.04)^{* *}$ & .23 \\
\hline Romantic partner & $.00(.04)$ & .00 \\
\hline \multicolumn{3}{|c|}{$\begin{array}{l}\text { Adolescent depressive symptoms and warmth and acceptance in } \\
\text { social context }\end{array}$} \\
\hline VIP & $-.02(.04)$ & -.04 \\
\hline Parent & $-.10(.03)^{* *}$ & -.21 \\
\hline Peer & $-.14(.04)^{* *}$ & -.28 \\
\hline Romantic partner & $-.04(.04)$ & -.08 \\
\hline \multicolumn{3}{|c|}{$\begin{array}{l}\text { Adolescent depressive symptoms and depressive symptoms in social } \\
\text { context }\end{array}$} \\
\hline VIP & $.25(.16)$ & .12 \\
\hline Peer & $.33(.11)^{* *}$ & .23 \\
\hline Romantic partner & $.08(.11)$ & .06 \\
\hline \multicolumn{3}{|c|}{ Adolescent problem behavior and problem behavior in social context } \\
\hline VIP & $.64(.26)^{*}$ & .17 \\
\hline Peer & $.52(.16)^{* *}$ & .24 \\
\hline Romantic partner & $.94(.19)^{* * *}$ & .35 \\
\hline
\end{tabular}

Americans), and examined the influence of VIPs when youth also have romantic partners. Overall, our results suggested that the influence of VIPs across ethnic groups is substantially similar, and that in two of the three outcomes measured in this study, VIPs remain influential even when adolescents are involved in romantic relationships.

An examination of the background characteristics of VIPs across ethnic groups revealed that the VIPs of Hispanic adolescents had lower levels of educational attainment than VIPs of Asian and European American adolescents. Additionally, although there were no apparent ethnic differences in employment status (employed vs. not employed), VIPs of Asian adolescents had higher levels of occupational prestige than VIPs of Hispanic and European American adolescents. Given that most VIPs are from adolescents' own ethnic group, it is not surprising that the characteristics of VIPs reflect broader ethnic differences in the population (Barringer et al. 1990).

Although there were ethnic differences in VIPs' background characteristics, the psychological profiles of VIPs were largely similar across ethnic groups. One interpretation of this result is that social capital is less important than psychological characteristics in the formation of adolescent-VIP relationships. We also found that adolescents in all three ethnic groups consistently viewed their VIPs in more positive terms than parents, peers and in some cases, romantic partners. For example, VIPs were rated higher in warmth and acceptance than parents and peers, and lower in levels of depressive symptoms and problem behaviors than peers. This set of findings is consistent with previous work suggesting that relationships with VIPs provide a unique niche for adolescents, in which they experience certain aspects peer-like relations with their important nonparental adult, while also benefiting from the VIP's positive adult qualities (Beam et al. 2002; DuBois and Silverthorn 2005; Greenberger et al. 1998). As noted at the outset, to our knowledge, no studies have examined mentor/VIPs characteristics and "effects" in relation to those of adolescents' romantic partners. The current study indicated that, across all ethnic groups, VIPs were perceived to offer a level of warmth and acceptance similar to that of romantic partners but were seen as having a lower level of depressive symptomatology. Furthermore, VIPs tended to be seen as engaging in fewer problem behaviors than romantic partners, although this finding attained significance only for Hispanic Americans. It appears that regardless of ethnicity, adolescents viewed their VIPs in a more favorable light than they viewed their parents, peers, and in some cases, romantic partners.

In moving beyond the descriptive data, we found that, with a few interesting exceptions, the associations between VIPs' characteristics and adolescent adjustment were largely similar across ethnic groups. For example, VIPs' warmth and acceptance was negatively associated with adolescents' depressive symptoms, and positively associated with adolescents' self-esteem across ethnic groups. Likewise, VIPs' problem behaviors had a positive association with adolescents' own problem behaviors across ethnic groups. This set of findings supports previous research on VIP-adolescent relations (Chen et al. 2003) as well as a long line of research on the similarities in developmental processes across ethnic groups (Rowe et al. 1994).

Interestingly, however, just as in Chen et al. (2003), a few of the correlations were significantly different across ethnic groups. One consistent difference between the current study and that of Chen et al. (2003) is that European Americans showed a higher correlation between their own and their VIP's problem behavior than did their comparison groups (Asian American and Hispanic adolescents in the current study; Chinese adolescents in Chen et al. (2003)). Chen et al. (2003) attributed the European American-Chinese difference just noted to the lower mean levels of (and smaller amount of variance in) problem behaviors among Chinese adolescents and their VIPs. Similarly, the current study showed lower levels of problem behaviors among Asian American adolescents, and additionally, Hispanics, than among European Americans. ${ }^{1}$

\footnotetext{
${ }^{1}$ European American adolescents reported higher levels of problem behaviors $(M=1.66, \mathrm{SD}=.64)$ than Asian American and Hispanic
} 
Reports of VIPs' problem behaviors showed a similar pattern of ethnic differences, but these differences were not statistically significant. Moreover, this explanation of ethnic differences also applies to the only significant ethnic difference in the associations between the psychological features of adolescents' other social contexts (e.g., parents, peers and romantic partners) and adolescent adjustmentthe association between peer problem behaviors and adolescent problem behaviors. European Americans reported higher peer problem behaviors with greater variance than did the other groups.

The other three ethnic differences in associations between VIP attributes and adolescent outcomes all involved adolescents' self-esteem. VIPs' problem behaviors were significantly negatively associated with adolescents' selfesteem among Hispanics, but not among Asian and European Americans, and VIPs' warmth and acceptance was more strongly associated with adolescents' self-esteem among Asian Americans than among European Americans. These results suggest that different aspects of VIPs may affect adolescents' self-esteem differently depending on cultural context, but more research is needed to replicate and explain these results. Plausible explanations may involve cultural differences in the value of positive self-regard and sources of self-esteem (Heine and Lehman 1997). It should be noted, however, that ethnic differences in correlates of adolescent outcomes are generally few in number (6 out of 90 in our study), some of which may have been statistical artifacts due to limited variance for certain groups. Overall, evidence from this and other studies is overwhelmingly in support of the "no more than skin-deep" hypothesis of similar developmental processes across ethnic groups (Rowe et al. 1994).

In support of our fourth hypothesis, VIPs made unique contributions to adolescent adjustment even after romantic partners were considered. Interestingly, the unique contributions were in the areas of adolescents' problem behaviors and self esteem, but not in their depressive symptoms. These results represent a major extension of previous research that showed unique contributions of VIPs' characteristics to adolescents' outcomes after parents' and peers' characteristics were considered (Chang et al. in press; Greenberger et al. 1998). Indeed, it is remarkable that, given the great importance of parents (Maccoby and Martin 1983) and peers (Brown and Larson 2009) in adolescent development, VIPs' roles appear robust enough to survive the statistical control of important social contexts such as parents, peers, and, now, romantic partners. In the case of problem behaviors, it is worth noting that romantic

Footnote 1 continued

adolescents $(M=1.36, \mathrm{SD}=.49$ and $M=1.38, \mathrm{SD}=.46$, respectively), with $F(2,353)=11.68, p<.001$ for the mean differences, and $F(2,353)=10.36, p<.001$ for Levene's test of inequality of variance. partner's role was also very strong and accounted for unique variance. This finding further supports Rhule-Louie and McMahon's (2007) notion that romantic relationships both influence, and are influenced by, problem behaviors in late adolescence and early adulthood.

The lack of VIPs' unique contributions (although it was a significant correlate at the bivariate level) to adolescents' depressive symptoms also deserves a brief comment. This result was similar to an earlier finding that VIPs' warmth and acceptance did not make a unique contribution to adolescents' depressive symptoms after controlling for parents' and peers' warmth and acceptance (Greenberger et al. 1998). This consistent finding may reflect the limit or constraint of VIPs' reach into adolescents' emotional wellbeing. Adolescents devote a great amount of time to peer and romantic relationships, which makes their well-being more susceptible to the influence of their friends' and romantic partner's depressive moods as well as their warmth and support (e.g., Barber and Eccles 2003; Furman and Schaffer 2003). Taken together, results of this study outlined the domains in which VIPs can make a difference (e.g., problem behaviors and self-esteem) and those in which they are less likely to (e.g., emotional well-being).

The current study had two noteworthy limitations. First, because data came from a cross-sectional study, we cannot infer causal relations between VIPs' characteristics and adolescent outcomes. Future research would benefit from longitudinal examinations of the long-term impact of VIPs on the lives of adolescents (see Chang et al. in press, for an example of the effects of earlier adolescent-VIP relations on adjustment during the first post-high school year). Second, all data were based on self-report measures obtained from the adolescents. It would be advantageous for future studies to obtain additional information using methods other than self-report, as well as to collect data from parents, peers, VIPs and romantic partners themselves. Follow-up studies that employ longitudinal designs and consult multiple informants are a necessary next step toward understanding the influences of VIPs on adolescents from various ethnic backgrounds.

From this study, we can draw two main conclusions. First, VIPs can play similarly important roles in the lives of adolescents from different ethnic backgrounds. For example, despite varying levels of social capital (e.g., educational attainment, occupational prestige), VIPs of all ethnic groups showed higher levels of warmth and acceptance than parents and peers, and lower levels of depressive symptoms and problem behaviors than peers, and in some cases, romantic partners. Furthermore, VIP characteristics appear to be equally important to adolescent outcomes, as shown by the mostly similar correlations across the three ethnic groups. Second, VIPs continue to be important in adolescents' lives, even when adolescents are involved in 
romantic relationships. For instance, VIPs continue to make unique contributions to adolescents' self-esteem and problem behaviors, even after the characteristics of adolescents' romantic partners are considered. In summary, the current study expands the body of literature on VIPs by providing further insight into how adolescent-VIP relationships function across ethnic groups and while adolescents are involved in romantic relationships.

Acknowledgments We are grateful to Jutta Heckhausen, C. David Dooley, Esther Chang, Susan P. Farruggia, Gary Germo, Laura M. Gil-Trejo, and Bernadeth Torres for their contributions to the larger project from which these data were drawn. We also thank the reviewers of an earlier version of this paper for suggestions that substantially improved it. Data collection was funded by the School of Social Ecology, Department of Psychology and Social Behavior, and the Max-Planck Award for International Cooperation (to Jutta Heckhausen) from the German Federal Ministry of Education and Research.

Open Access This article is distributed under the terms of the Creative Commons Attribution Noncommercial License which permits any noncommercial use, distribution, and reproduction in any medium, provided the original author(s) and source are credited.

\section{References}

Barber, B., \& Eccles, J. (2003). The joy of romance: Healthy adolescent relationships as an educational agenda. In P. Florsheim (Ed.), Adolescent romantic relations and sexual behavior: Theory, research, and practical implications. Mahwah, NJ: Lawrence Erlbaum Associates.

Barringer, H. R., Takeuchi, D. T., \& Xenos, P. (1990). Education, occupational prestige, and income of Asian Americans. Sociology of Education, 62, 27-43.

Beam, M. R., Chen, C., \& Greenberger, E. (2002). The nature of adolescents' relationships with their "very important" nonparental adults. American Journal of Community Psychology, 30, 305-325.

Brown, B. B., \& Larson, J. (2009). Peer relationships in adolescence. In R. M. Lerner \& L. Steinberg (Eds.), Handbook of adolescent psychology: Vol. 2: Contextual influences on adolescent development (pp. 74-103). New Jersey: Wiley.

Chang, E. S., Greenberger, E., Chen, C., Heckhausen, J., \& Farruggia, $\mathrm{S}$. (in press). Non-parental adults as social resources in the transition to adulthood. Journal of Research on Adolescence.

Chen, C., Greenberger, E., Farruggia, S., Bush, K., \& Dong, Q. (2003). Beyond parents and peers: The role of important nonparental adults (VIPs) in adolescent development in China and the United States. Psychology in the Schools, 40, 35-50.

Chen, C., Greenberger, E., Lester, J., Dong, Q., \& Guo, M. (1998). A cross-cultural study of family and peer correlates of adolescent misconduct. Developmental Psychology, 34, 770-781.

Collins, A. W., \& Laursen, B. (2004). Changing relationships, changing youth: Interpersonal contexts of adolescent development. Journal of Early Adolescence, 24, 55-62.

Connolly, J., Craig, W., Goldberg, A., \& Pepler, D. (1999). Conceptions of cross-sex friendships and romantic relationships in early adolescence. Journal of Youth and Adolescence, 28, 481-494.
Darling, N., Hamilton, S., Toyokawa, T., \& Matsuda, S. (2002). Naturally occurring mentoring in Japan and the United States: Social roles and correlates. American Journal of Community Psychology, 30, 245-270.

Davilla, J., Steinberg, S. J., Kachadourian, L., Cobb, R., \& Fincham, F. (2004). Romantic involvement and depressive symptoms in early and late adolescence: The role of a preoccupied relationships style. Personal Relationships, 11, 161-178.

DuBois, D. L., Holloway, B. E., Valentine, J. C., \& Cooper, H. (2002). Effectiveness of mentoring programs for youth: A metaanalytic review. American Journal of Community Psychology, 30, 157-197.

DuBois, D. L., \& Karcher, M. A. (Eds.). (2005). Handbook of youth mentoring. Thousand Oaks, CA: Sage.

DuBois, D. L., \& Silverthorn, N. (2005). Characteristics of natural mentoring relationships and adolescent adjustment: Evidence from a national study. Journal of Primary Prevention, 26, 69-92.

Farruggia, S. B., Greenberger, E., Chen, C., \& Heckhausen, J. (2006). Perceived social environment and adolescents' well-being and adjustment: Comparing a foster care sample with a matched sample. Journal of Youth and Adolescence, 35, 349-358.

Furman, W., \& Schaffer, L. (2003). The role of romantic relationships in adolescent development. In P. Florsheim (Ed.), Adolescent romantic relations and sexual behavior: Theory, research, and practical implications. Mahwah, NJ: Lawrence Erlbaum Associates.

Furman, W., Simon, V. A., Shaffer, L., \& Bouchey, H. A. (2002). Adolescents' working models and styles for relationships with parents, friends, and romantic partners. Child Development, 73, 241-255.

Greenberger, E., Chen, C., \& Beam, M. (1998). The role of "very important" nonparental adults in adolescent development. Journal of Youth and Adolescence, 27, 321-343.

Heine, S. J., \& Lehman, D. R. (1997). The cultural construction of self-enhancement: An examination of group-serving biases. Journal of Personality and Social Psychology, 72, 1268-1283.

Klaw, E. L., Rhodes, J. E., \& Fitzgerald, L. F. (2003). Natural mentors in the lives of African American adolescent mothers: Tracking relationships over time. Journal of Youth and Adolescence, 32, 223-232.

Maccoby, E. \& Martin, J. (1983). Socialization in the context of the family: Parent-child interaction. In E. M. Hetherington (Ed.), P. H. Mussen (Series Ed.), Handbook of child psychology: Vol. 4. Socialization, personality, and social development (pp. 1-101). New York: Wiley.

McMahon, M., \& Wilkinson, R. B. (2005). Attachment relationships and adolescent psychological health: The influence of romantic relationships. Proceedings from the 5th Annual Conference of the Australian Psychological Society's Psychology of Relationships Interest Group (pp. 101-106). Melbourne, Australia: The Australian Psychological Society.

Nakao, K., \& Treas, J. (1994). Updating occupational prestige and socioeconomic status scores: How the new measures measure up. Sociological Methodology, 24, 1-72.

Neeman, J., Hubbard, J., \& Masten, A. (1995). The changing importance of romantic relationship involvement to competence from late childhood to late adolescence. Developmental and Psychopathology, 7, 727-750.

Overbeek, G., Vollenberg, W., Engels, R. C., \& Meeus, W. (2003). Parental attachment and romantic relationships: Associations with emotional disturbance during late adolescence. Journal of Counseling Psychology, 50, 28-39.

Radloff, L. S. (1977). The CES-D scale: A self-report depression scale for research in the general population. Applied Psychological Measurement, 1, 385-401. 
Rhodes, J. E., Contreras, J. M., \& Mangelsdorf, S. C. (1994). Natural mentor relationships among Latina adolescent mothers: Psychological adjustment, moderating processes, and the role of early parental acceptance. American Journal of Community Psychology, 22, 211-227.

Rhodes, J. E., Ebert, L., \& Fisher, K. (1992). Natural mentors: An overlooked resource in the social networks of young, African American mothers. American Journal of Community Psychology, 20, 445-461.

Rhodes, J. E., Reddy, R., Grossman, J. B., \& Lee, J. M. (2002). Volunteer mentoring relationships with minority youth: An analysis of same- versus cross-race matches. Journal of Applied Social Psychology, 32, 2114-2133.

Rhule-Louie, D. M., \& McMahon, R. J. (2007). Problem behavior and romantic relationships: Assortative mating, behavior contagion, and desistance. Clinical Child and Family Psychology Review, $10,53-100$.

Rosenberg, M. (1965). Society and the adolescent self-image. Princeton, NJ: Princeton University Press.

Rowe, D. C., Vazsonyi, A. T., \& Flannery, D. J. (1994). No more than skin deep: Ethnic and racial similarity in developmental process. Psychological Review, 101, 396-413.

Sanchez, B., Esparza, P., \& Colón, Y. (2008). Natural mentoring under the microscope: An investigation of mentoring relationships and Latino adolescents' academic performance. Journal of Community Psychology, 36, 468-482.

Wissink, I. B., Deković, M., \& Meijer, A. M. (2009). Adolescent friendship relations and developmental outcomes: Ethnic and gender differences. Journal of Early Adolescence, 29, 405-425.

Zimmer-Gembeck, M. J., Siebenbruner, J., \& Collins, W. A. (2001). Diverse aspects of dating: Associations with psychosocial functioning from early to middle adolescence. Journal of Adolescence, 24, 313-336.
Zimmerman, M. A., Bingenheimer, J. C., \& Notaro, P. C. (2002). Natural mentors and adolescent resiliency: A study with urban youth. American Journal of Community Psychology, 30, 221-243.

\section{Author Biographies}

Eileen Haddad is a doctoral student in the Department of Psychology and Social Behavior at the University of California-Irvine. She received her M.A. in Social Ecology from the University of California-Irvine. Her current research interests include social influences on adolescent and young adult development.

Chuansheng Chen is a professor in the Department of Psychology and Social Behavior at the University of California-Irvine. He received his Ph.D. in Developmental Psychology from the University of Michigan. His current research interests include cross-cultural adolescent and young adult development and the neural bases of learning.

Ellen Greenberger is Research Professor in the Department of Psychology and Social Behavior, and Edward A. Dickson Emeriti Professor at the University of California-Irvine. She received her Ph.D. in Clinical Psychology from Harvard University. Her current research interests include cross-cultural and ethnic similarities and differences in adolescents' relationships with parents and significant others. 